\title{
Recognition well deserved
}

2014 marks the beginning of the 28th volume of this Journal and it $L_{\text {heralds a significant and long-awaited change. Since 1994, the }}$ Canadian Journal of Gastroenterology has been the official journal of the Canadian Association of Gastroenterology (CAG). During those 20 years, however, the Journal was also strongly supported by hepatologists as was evidenced by the composition of the editorial boards and the editorial content.

One of the two founding Co-Editors-in-Chief, Dr Noel Williams, is a hepatologist. The second Editor-in-Chief, Dr Lloyd Sutherland, along with Dr Williams, was instrumental in founding the Canadian Society for the Study of the Liver (CASL). The third Editor-in-Chief, Dr Paul Adams, is also a hepatologist. In fact, the majority of the Editor-in-Chiefs of this Journal have been hepatologists.

In 2001, the Canadian Journal of Gastroenterology also became the official journal of CASL and, in 2011, Pulsus Group began providing CASL with a percentage of revenues related to the Journal. Given the contributions made by Canadian hepatologists to this publication, it is more than appropriate that they be officially recognized by changing the title of the Journal to the Canadian Journal of Gastroenterology $\mathbb{E}$ Hepatology.

We recognize their contribution, we thank them for their constant support and we now officially recognize their importance to the Journal...welcome to the Canadian Journal of Gastroenterology $\mathbb{E}$ Hepatology!

Robert B Kalina Publisher 


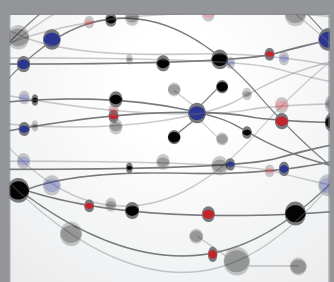

The Scientific World Journal
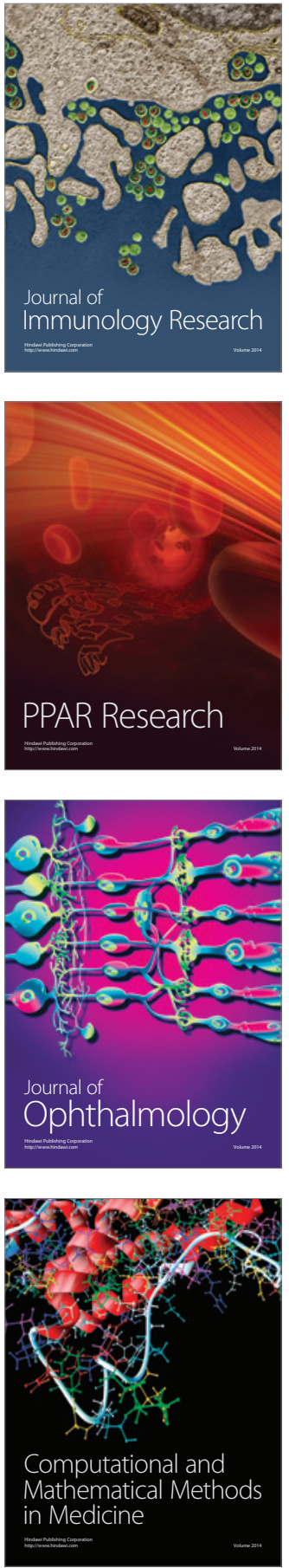

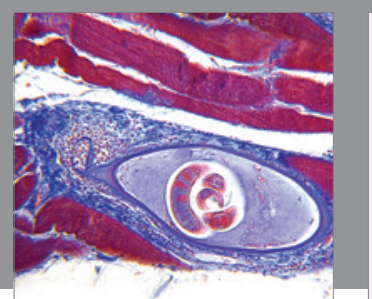

Gastroenterology Research and Practice

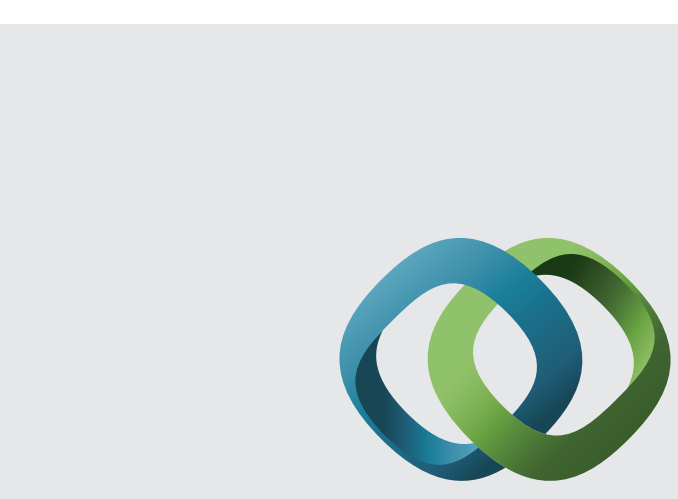

\section{Hindawi}

Submit your manuscripts at

http://www.hindawi.com
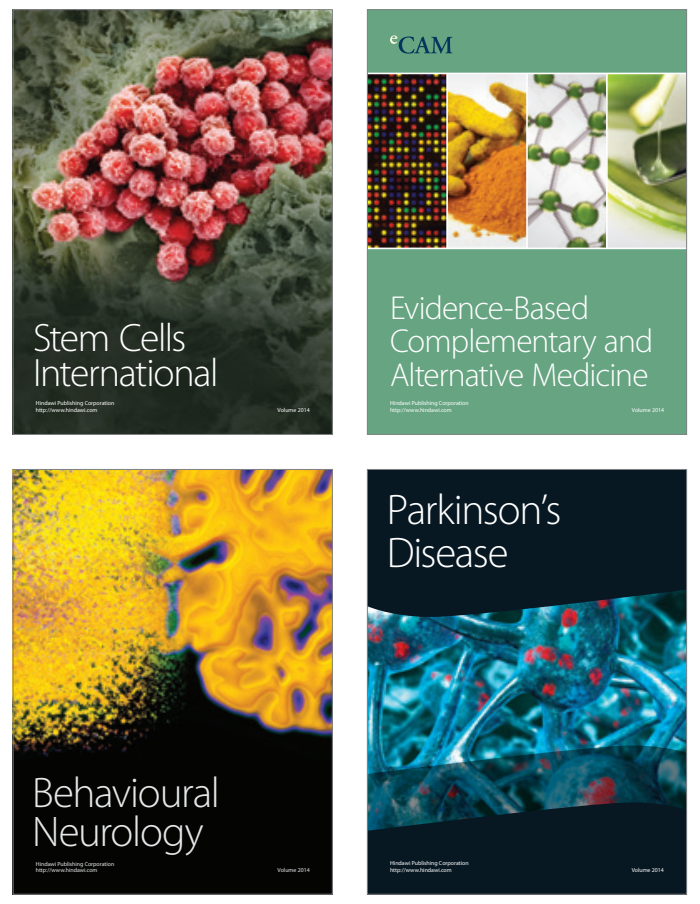
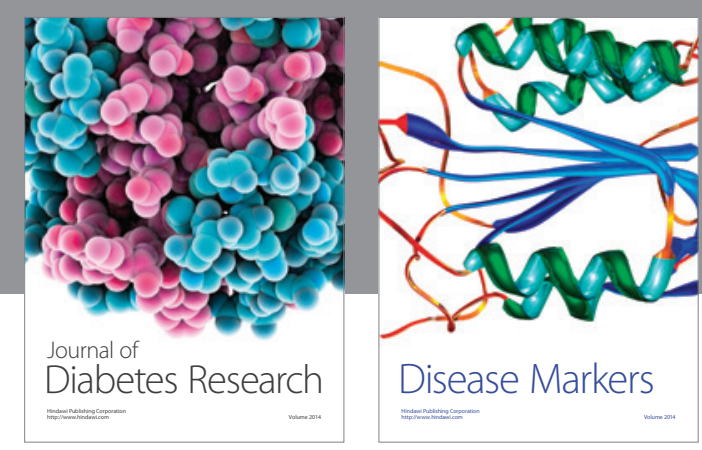

Disease Markers
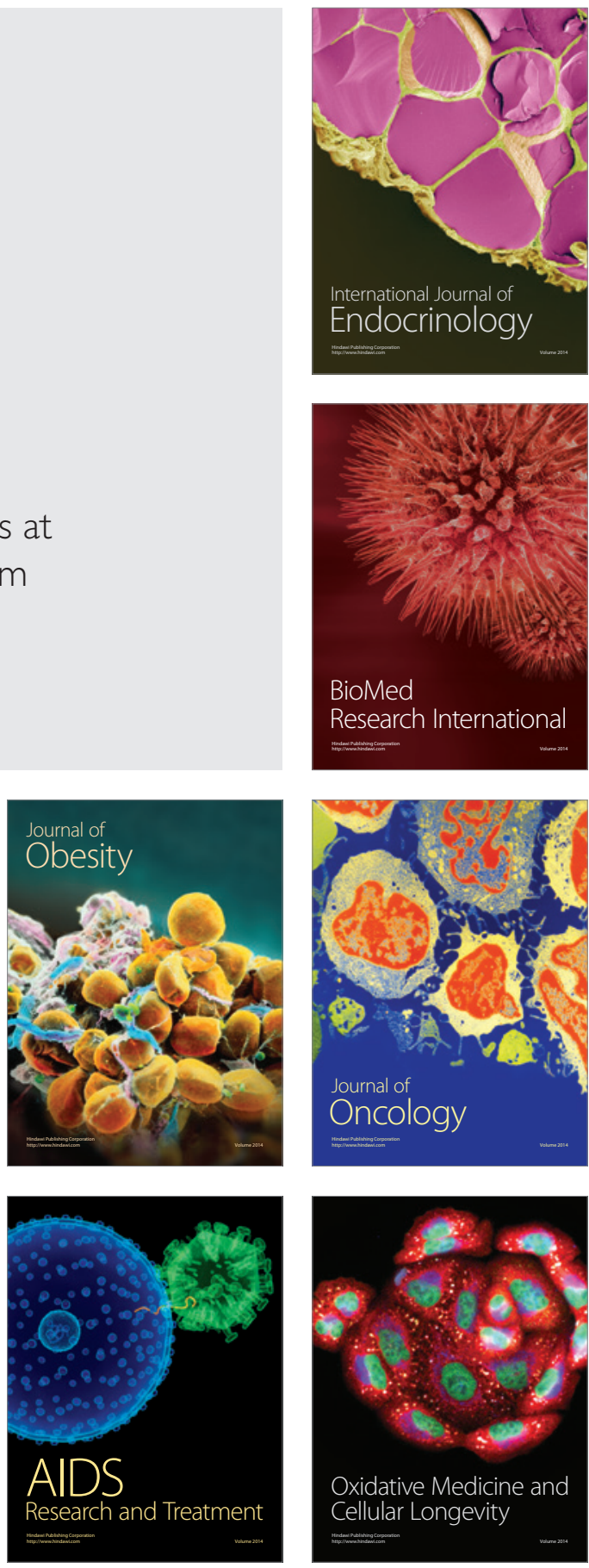